\title{
A NOVA PEDAGOGIA DA HEGEMONIA E A INCLUSÃO SOCIAL
}

\author{
Leonardo Docena Pina*
}

leodocena@yahoo.com.br

\section{RESUMO}

O presente artigo busca refletir sobre as implicações ideológicas da inclusão social. Para isso, analisa a função educativa de conceitos como "sociedade inclusiva", "empresa inclusiva", "acessibilidade" e "equiparação de oportunidades". O texto situa a inclusão social como uma ideologia, que afirma a viabilidade de um capitalismo de face humanizada, e que se constitui como um desdobramento das políticas hegemônicas do neoliberalismo.

Palavras-chave: Inclusão social. Ideologia. Hegemonia.

\section{THE NEW PEDAGOGY OF THE HEGEMONY AND THE SOCIAL INCLUSION}

\begin{abstract}
This article intends to reflect about the ideological implications of the social inclusion. For it, analyses the educative function of the concepts as "inclusive society", "inclusive business", "accessibility" and "equalization of the opportunities". The text situates the social inclusion as one ideology that affirms the viability of the capitalism with human face and that is result of neoliberal policies.
\end{abstract}

Keywords: Social inclusion. Ideology. Hegemony.

\section{Introdução}

O presente texto adota, como referencial norteador, a construção teórica sistematizada em Neves (2005) e Neves (2010), que evidencia a existência de um movimento de novo tipo, a Nova Pedagogia da Hegemonia. Com base nesses estudos, que se fundamentam nas formulações de Antonio Gramsci, torna-se possível elucidar a relação entre o discurso da inclusão social e os processos pedagógicos sob os quais a classe trabalhadora está submetida nos dias de hoje.

Uma primeira reflexão que constitui nosso ponto de partida é a de que as formações sociais capitalistas compreendem um "bloco histórico" (GRAMSCI, 2000) no qual estrutura e superestrutura se constituem através de um nexo necessário e vital, e não através de uma relação de causa-efeito onde a superestrutura se constituiria como resultado mecânico do plano estrutural.

O conceito de bloco histórico ainda nos ajuda a compreender a relação estabelecida entre sociedade civil e sociedade política. Nas "sociedades ocidentais", onde força e consentimento - em justa relação - garantem a dominação de classe, a relação entre aparelho de Estado e sociedade civil caracteriza um processo de ampliação do Estado: se, antes, este era caracterizado exclusivamente como "sociedade política", depois, com a elevação da organização popular e o aumento da organização da própria burguesia para manter seus interesses, o fenômeno Estado passou a incorporar a sociedade civil como uma 
de suas instâncias de poder.

O Estado Ampliado - "sociedade política + sociedade civil, isto é, hegemonia encouraçada de coerção" (GRAMSCI, 2000, p. 244) - relaciona-se a outro conceito que constitui nosso ponto de partida: o de "Estado Educador". Expressão dos conflitos de interesse, o Estado Ampliado cumpre a função educativa de permitir a organização da cultura sob determinada direção de classe. Ou seja, ao Estado impõe-se a complexa tarefa de formar um certo tipo de "homem coletivo", de conformar técnica e eticamente as massas populares à sociabilidade burguesa ${ }^{1}$ (NEVES, 2005). Portanto, outra reflexão importante que fundamenta nosso estudo centra-se na função educativa do Estado capitalista, que é - dirigida pelo bloco no poder e - implementada nas instâncias da aparelhagem estatal e nas organizações da sociedade civil, de modo a ordenar a experiência cultural de vida e fazer com que todos passem a sentir, pensar e agir com base em referências capazes de suprimir práticas contra-hegemônicas (MARTINS, 2010).

Essa organização da cultura em torno de referências que reforçam a dominação realizada pela classe dominante sobre o conjunto da sociedade é o que caracteriza o conceito de hegemonia. Por hegemonia, entende-se, na compreensão gramsciana, um complexo processo de relações vinculadas ao exercício do poder no capitalismo, o qual se materializa a partir de uma concepção de mundo e da prática política de uma classe ou fração de classe. Gramsci (1999) situa o exercício da hegemonia como uma relação pedagógica que busca subordinar, em termos morais e intelectuais, diferentes grupos sociais, por meio da persuasão e da educação. Trata-se de um conceito que expressa o movimento realizado por uma classe ou frações de classe para convencer e organizar o consenso em torno de uma concepção particular de mundo, de modo a transformar seu projeto particular em uma concepção aceita pela maioria (MARTINS e NEVES, 2010).

Para compreender as mudanças nos processos educativos voltados à formação da sociabilidade atualmente, torna-se importante considerar o entendimento de que a reorganização social, política e econômica, nos anos de pós-guerra, definiu um padrão de sociabilidade adequado à reprodução do capital naquele contexto; contudo, a crise que se abateu sobre o capitalismo nos anos de 1970/80, levando ao esgotamento da Era de Ouro, provocou a superação do regime de acumulação fordista pelo regime de acumulação flexível e a consolidação do neoliberalismo como tentativas capitalistas para recuperar os patamares de expansão anteriores (HARVEY, 2007).

As mudanças ocorridas para gerir a crise trouxeram novas implicações para a sociabilidade, sobretudo porque o trabalhador educado no pós-guerra - para se adequar à disciplina keynesianista e ao ambiente político que tendia predominantemente à estabilidade - não atendia mais aos anseios da classe dominante. A restrição do acesso ao emprego, aos direitos sociais e ao consumo evidenciava a necessidade de redefinir os parâmetros do conformismo social. Como descreve Martins (2009), para a conformação social de base neoliberal, governos como o de Thatcher e o de Reagan, por exemplo, implementaram medidas destinadas a "educar" os movimentos sindicais através da coerção. Dentre as políticas públicas neoliberais que se constituíram como importantes instrumentos de legitimação da sociabilidade burguesa encontram-se aquelas voltadas ao enfraquecimento das formas coletivas de representação de interesses dos trabalhadores, ao fechamento dos canais de negociação coletiva dos contratos de trabalho, à flexibilização dos direitos trabalhistas, à focalização do atendimento aos mais pobres, dentre outras que procuraram reforçar o pragmatismo, o empreendedorismo, a competitividade, a atomização e a ênfase na liberdade individual como referências a serem adotadas para a formação do novo homem coletivo (MARTINS, 2009).

No final da década de 1990, porém, o projeto neoliberal não havia recuperado as 
taxas de crescimento do conjunto da economia nem consolidado a coesão social. Esse quadro propiciou a construção de um movimento voltado à revisão do neoliberalismo, de tal modo que o crescimento econômico fosse recuperado em bases políticas que não gerassem tantos abalos na coesão social. Segundo Martins (2009), podem ser apontados como expressões de maior visibilidade desse movimento os "Novos Democratas", nos Estados Unidos, e o "Novo Trabalhismo", na Inglaterra, os quais foram responsáveis pelas definições programáticas e articulações políticas que possibilitaram a eleição de Bill Clinton, em 1992, e Tony Blair, em 1997. Conforme explica o autor, tal movimento revisionista foi registrado em outros países europeus, mas, também, na periferia do sistema, em Estados de elevado grau de industrialização e de ocidentalização, como foi o caso do Brasil, com a eleição de Fernando Henrique Cardoso, em 1994.

Pensado como caminho alternativo aos efeitos negativos do neoliberalismo e às insuficiências da social democracia européia, esse movimento, denominado de "Terceira Via", procurou apresentar uma nova agenda política-econômica para o mundo nos limites do capitalismo ${ }^{2}$. Em linhas gerais, pode-se dizer que a Terceira Via considera que algumas políticas neoliberais, embora tenham sido necessárias, ameaçaram seriamente o grau de estabilidade político-social (GUIDDENS, 2001b). Por essa razão, entende ser necessário preservar o modo capitalista de produção da existência humana, mas atribuindo-lhe uma face mais humanizada, por meio do "livre mercado" com "justiça social".

Segundo Neves (2005), o desenvolvimento do projeto da Terceira Via no Brasil, a partir da década de 1990, vem sendo marcado por um conjunto de estratégias voltadas à legitimação de um novo padrão de sociabilidade, capaz de assegurar o exercício da dominação de classe por meio de processos educativos positivos. Esse conjunto de estratégias - que envolve um intenso e articulado processo de difusão de valores, ideias e práticas sociais orientadas pela repolitização da política ${ }^{3}$ - foi denominado por Neves (2005) de Nova Pedagogia da Hegemonia. Trata-se de uma educação para o consenso que busca garantir a coesão social nos moldes de uma nova sociabilidade, na qual os sentidos de democracia, cidadania, ética e participação, por exemplo, são redefinidos de acordo com os interesses privados do capital nacional e internacional.

Neste contexto, em que predominam os processos pedagógicos voltados à formação da nova sociabilidade, o exercício da dominação envolve a difusão de ideologias que buscam legitimar referências ou estratégias econômicas, políticas, científicas, filosóficas e/ou culturais fundamentadas na teorização antimarxista e no projeto político da Terceira Via. É nesse contexto que o tratamento das condições de inferioridade social vividas por grupos historicamente discriminados passaram a assumir importante papel educativo, qual seja, o de mostrar a legitimidade do projeto histórico dominante. A partir de ações paliativas, que buscam minimizar os efeitos degradantes do capitalismo, a coesão social vai se fortalecendo na medida em distintos grupos sociais se subordinam à hegemonia da classe dominante. Assim, os indivíduos que apresentam condições objetivas para desestruturar o consenso burguês, frequentemente denominados de excluídos, tendem a ser convencidos de que um capitalismo humanizado, na forma de sociedade inclusiva, por exemplo, seria a melhor ou a única forma possível de resolver os problemas sociais a que estão expostos.

O presente texto, com base no referencial descrito, busca apreender as implicações ideológicas da inclusão social no atual cenário histórico, político e ideológico. Para tanto, questiono: a inclusão desempenha alguma função educativa importante para legitimar o novo projeto histórico hegemônico? Quais são as implicações ideológicas da inclusão social? A inclusão revela capacidade para produzir uma vontade coletiva afinada com os interesses da classe dominante? Buscando responder essas questões centrais, parto da 
análise de alguns conceitos que dão forma às formulações centrais da inclusão social. Essas formulações, aqui denominadas de teses, foram captadas em Sassaki (1999), importante intelectual defensor e difusor da inclusão social no Brasil. A análise desenvolvida neste trabalho pode contribuir para o debate sobre o tema, sobretudo porque destaca as implicações ideológicas das teses em questão, sem, contudo, deixar de reconhecer seus avanços no sentido de melhorar as condições de vida de grupos sociais específicos.

\section{Limitações e implicações ideológicas da inclusão social nos marcos do capitalismo}

O paradigma da inclusão responde à necessidade de tratamento de um problema frequentemente denominado de "exclusão social". Embora seja importante compreender esse fenômeno para além de sua aparência imediata, não há espaço para esse debate no presente texto, razão que me permite avançar para outros questionamentos. Pina e Martins (2010) já realizaram um estudo crítico sobre essa temática ${ }^{4}$. Vale destacar que Pina e Martins (2010) criticam o entendimento de que a exclusão não decorre das relações sociais de produção, além de comprovar que esse problema social não pode ser resolvido sem a superação das relações capitalistas. A partir dessa constatação dos autores, podemos questionar se a inclusão social realmente busca superar a exclusão. Conceitos como sociedade inclusiva, empresa inclusiva, acessibilidade, equiparação de oportunidades são analisados, nesta seção, juntamente com as teses centrais que neles se fundamentam. Assim, pretendo evidenciar não só as limitações da inclusão social como, também, suas implicações ideológicas no interior do capitalismo.

Tese 1: a inclusão contribui para construir um novo tipo de sociedade

A primeira tese a ser analisada é a de que a inclusão social é um processo que contribui para a construção de um novo tipo de sociedade: a "sociedade inclusiva" ou "sociedade para todos".

De acordo com Sassaki (1999), o movimento da inclusão social começou inicialmente na segunda metade dos anos de 1980 nos países mais desenvolvidos e, na década de 1990, tomou impulso também em "países em desenvolvimento". Sob a ótica de Sassaki (1999, p.17), o objetivo desse movimento "é a construção de uma sociedade realmente para todas as pessoas, sob a inspiração de novos princípios". Dentre os princípios a que se refere o autor, pode-se destacar: celebração das diferenças, direito de pertencer, valorização da diversidade humana, solidariedade humanitária, igual importância das minorias e cidadania com qualidade de vida. Para construir a "sociedade para todos", o paradigma da inclusão reconhece ser necessário superar a exclusão a que estão sujeitos muitos indivíduos por meio de um processo de adaptação:

Conceitua-se inclusão social como o processo pelo qual a sociedade se adapta para poder incluir, em seus sistemas sociais gerais, pessoas com necessidades especiais e, simultaneamente, estas se preparam para assumir seus papéis na sociedade. A inclusão social constitui, então, um processo bilateral no qual as pessoas, ainda excluídas, e a sociedade buscam, em parceria, equacionar problemas, decidir sobre soluções e efetivar a equiparação de oportunidades para todos (SASSAKI, 1999, p.41). 
O conceito de inclusão social evidencia uma tentativa de superar a "exclusão" a partir de um processo de adaptação da sociedade para "incluir" em seus "sistemas sociais gerais" aqueles indivíduos que se encontram "excluídos". Aparentemente, isso pode ser considerado um avanço na tentativa de superar as condições de "exclusão", visto que o foco é colocado sobre a "sociedade", tal com explica Sassaki (2005, p. 21): "para incluir todas as pessoas, a sociedade deve ser modificada a partir do entendimento de que ela é que precisa ser capaz de atender às necessidades de seus membros". Ou seja, nessa afirmação está evidente a ideia de que o problema não está concentrado nas diferenças do indivíduo, mas na característica (excludente) da sociedade. Durante muito tempo, prevaleceu a ideia de que o problema da "exclusão" era decorrente dos próprios "excluídos", considerados desviantes do padrão de normalidade. Nesse caso, cabia aos próprios indivíduos adaptar-se para superar as condições de inferioridade social a que estavam sujeitos, pois eram as diferenças individuais que estavam no centro da questão. As características da sociedade não eram, até então, questionadas. O princípio da inclusão avança no sentido de evidenciar que, na verdade, o problema concentra-se na sociedade, que não está adaptada para atender às necessidades de todas as pessoas. Daí o entendimento de que a esta deve ser modificada para eliminar os fatores que geram a exclusão:

a inclusão consiste em adequar os sistemas sociais gerais da sociedade de tal modo que sejam eliminados os fatores que excluam certas pessoas do seu seio e mantinham afastadas aquelas que foram excluídas. A eliminação de tais fatores deve ser um processo contínuo e concomitante com o esforço que a sociedade deve empreender no sentido de acolher todas as pessoas, independentemente de suas diferenças individuais e das suas origens na diversidade humana (SASSAKI, 2005, p.21).

Ao considerar a inclusão no conjunto das relações sociais, pode-se afirmar que as modificações propostas por esse princípio são importantes, mas insuficientes. A adaptação proposta não consiste em uma transformação radical da sociedade. Trata-se de alterações superficiais que mantêm em funcionamento o modo capitalista de produção da existência, o qual não deixará de deslocar pessoas ou grupos sociais para as margens da sociedade. Para compreender a insuficiência das ações da inclusão, podemos recorrer a reflexões sobre a chamada sociedade inclusiva.

Para Sassaki (1999), o processo de inclusão social vem sendo efetivado em diferentes setores sociais, tais como educação, lazer e transporte. Quando isso acontece, fala-se em "educação inclusiva", "lazer inclusivo" e "transporte inclusivo". Outra forma utilizada para designar a aplicação do referido processo nesses diferentes setores é a utilização de expressões como "educação para todos", "lazer para todos", "transporte para todos" (SASSAKI, 1999). A disseminação do processo de inclusão social nos diferentes setores sociais culminaria com a construção da chamada "sociedade inclusiva" ou "sociedade para todos". Isso é o que pressupõe Sassaki (1999, p. 42, grifos do autor): "Quanto mais sistemas comuns da sociedade adotarem a inclusão, mais cedo se completará a construção de uma verdadeira sociedade para todos - a sociedade inclusiva". Construída a partir da adequação dos espaços sociais gerais e também de uma mudança de mentalidade das pessoas, a sociedade inclusiva significaria a consolidação de um novo tipo de sociedade, alcançada através do desenvolvimento do processo de inclusão social:

a inclusão, portanto, é um processo que contribui para a construção de um novo tipo de sociedade através de transformações pequenas e grandes, 
nos ambientes físicos (espaços internos e externos, equipamentos, aparelhos e utensílios, mobiliário e meios de transporte) e na mentalidade de todas as pessoas, portanto, também do próprio portador de necessidades especiais (SASSAKI, 1999, p.42).

Ao contrário do que supõe o princípio da inclusão, a "sociedade inclusiva" não consiste em um novo tipo de sociedade. Trata-se apenas de uma nova face dada à velha ordem social capitalista, qual seja, a de um capitalismo menos selvagem, isto é, humanizado. O capitalismo é uma sociedade produtora de mercadorias. Assim, tudo, no interior desse modo de produção, tende a se transformar em mercadoria, inclusive a força de trabalho. Um pressuposto fundamental desse modelo de sociedade é a dissociação entre os trabalhadores e a propriedade dos meios pelos quais realizam o trabalho. Essa dissociação formou duas espécies diferentes de possuidores de mercadoria: de um lado, o proprietário de dinheiro, de meios de produção e de meios de subsistência, interessado em produzir capital; de outro lado, o trabalhador, detentor apenas de sua força de trabalho, que a vende como condição para manter sua própria existência. Essa divisão, que mantém sua essência até os dias de hoje, não é atacada pela inclusão social. Seguindo a tendência de entender que o "problema da atualidade" não é a exploração, mas a "exclusão", o processo de inclusão social defendido por Sassaki (1999) não se propõe a superar as leis do mercado, mas, apenas, modificá-las para que os portadores de deficiência tenham maiores oportunidades de vender sua força de trabalho. A participação no mercado é, inclusive, o fim último da inclusão, pois, conforme afirma Sanchez (2005, p. 14), "Está implícita na inclusão social, a participação no mercado de trabalho competitivo, sendo este o fim último da inclusão".

Sob a ótica de Sassaki (1999, p. 60),

O mercado de trabalho, no passado, pode ser comparado a um campo de batalha: de um lado, as pessoas com deficiência e seus aliados empenhando-se arduamente para conseguir alguns empregos; e de outro, os empregadores, praticamente despreparados e desinformados sobre a questão da deficiência, recebendo ataques furiosos por não preencherem as vagas com candidatos portadores de deficiência tão qualificados quanto os candidatos não-deficientes.

O "no passado" a que se refere o autor consiste na chamada "fase da exclusão", na qual "a pessoa com deficiência não tinha nenhum acesso ao mercado de trabalho competitivo" (SASSAKI, 1999, p.60). Trata-se da fase em que "a humanidade considerava uma crueldade a idéia de que pessoas deficientes trabalhassem" (SASSAKI, 1999, p.60), visto que "empregar pessoas deficientes era tido como uma forma de exploração que deveria ser condenada por lei" (SASSAKI, 1999, p.60). Sob o ponto de vista da inclusão, os dias de hoje devem configurar uma nova fase na qual as pessoas com deficiência sejam inseridas no mercado. Vale ressaltar que o paradigma da inclusão entende que o mercado de trabalho não deve ser constituído pelo antagonismo entre as classes sociais, visto que, em seu entendimento, trabalhadores e capitalistas deveriam enfrentar juntos os desafios da produtividade e competitividade. Dessa forma, se, na "fase da exclusão", o mercado de trabalho poderia ser comparado a um campo de batalha, composto, de um lado, pelos capitalistas e, de outro lado, pelos trabalhadores (sejam eles deficientes ou não deficientes),

na atual fase da inclusão, o mundo do trabalho tende a não ter dois lados. Agora, os protagonistas, em geral, parecem querer enfrentar juntos o desafio da produtividade e competitividade. A idéia que começou a 
vingar timidamente é a de que não haverá mais batalhas e muito menos vencedores e vencidos. Surge, então, no panorama do mercado de trabalho a figura da empresa inclusiva (SASSAKI, 1999, p.65).

Para Sassaki (1999, p.65), empresa inclusiva é

aquela que acredita no valor da diversidade humana, contempla as diferenças individuais, efetua mudanças fundamentais nas práticas administrativas, implementa adaptações nos ambientes físicos, adapta procedimentos e instrumentos de trabalho, treina todos os recursos humanos na questão da inclusão etc. Uma empresa pode tornar-se inclusiva por iniciativa e empenho dos próprios empregadores, que para tanto buscam informações pertinentes ao princípio da inclusão, e/ou com a assessoria de profissionais inclusivistas que atuam em entidades sociais.

Aparentemente, a "empresa inclusiva" pode significar um avanço em relação à "empresa comum", visto que aquela possibilita às pessoas com deficiência uma ampliação da possibilidade de garantir sua própria sobrevivência, a partir da venda de sua força de trabalho. Da mesma forma, pode-se considerar um avanço o reconhecimento da pessoa com deficiência como indivíduo com capacidades laborativas. Entretanto, ao visualizar esses deslocamentos levando em consideração a totalidade da vida social, pode-se afirmar que tais avanços se deram de modo a representar vantagem para o acúmulo de capital. Nenhuma das modificações propostas pela chamada empresa inclusiva visa alterar a essência das relações sociais capitalistas. Isso impede a efetiva absorção de todas as pessoas com deficiência, visto que a própria dinâmica capitalista implica a formação de um exército de reserva, que empurra grande parte dos trabalhadores para as margens do mercado.

Se, por um lado, a manutenção da dinâmica capitalista determina a esterilidade dos esforços direcionados à inserção das pessoas com deficiência no mercado de trabalho, fazendo-as engrossar o exército de reserva junto aos outros "excluídos" (LANCILLOTTI, 2003); por outro lado, isso não significa que a efetivação do processo de inclusão não permita a absorção de alguns desses indivíduos pelo mercado, pois, conforme explica Eagleton (2005), o capitalismo tende a criar inclusões e exclusões para seus próprios fins ou então lança mão das que já existem. $\mathrm{O}$ autor explica que, por um lado, o capitalismo tem levado massas inteiras de homens e mulheres à miséria e à indignidade de uma cidadania de segunda classe, mas, por outro lado, em princípio, o capitalismo é um credo impecavelmente inclusivo: "não se importa, realmente, com quem ele está explorando. É admiravelmente igualitário em sua pronta disposição de arrasar praticamente qualquer um" (EAGLETON, 2005, p.34-35).

Nem mesmo os índices de desemprego decorrentes da dinâmica capitalista constituem, para a inclusão, um motivo para os trabalhadores visualizarem os capitalistas como membros de uma classe antagônica. Pelo contrário, para Sassaki (1999, p.75), a "inclusão no mercado de trabalho competitivo não é um sonho impossível de ser realizado, desde que os empregadores sejam tratados como parceiros". Com essa formulação, duas importantes implicações ideológicas da inclusão tornam-se evidentes. A primeira delas é fazer com que as pessoas com deficiência - pertencentes à classe trabalhadora - acreditem na possibilidade de serem incluídas no mercado de trabalho por meio do processo de inclusão social. A ideia é buscar o convencimento de que as modificações superficiais defendidas pela inclusão dão conta de promover a absorção das pessoas com deficiência pelo mercado. Dessa forma, acreditando que a inclusão no mercado de trabalho 
competitivo é um sonho possível, torna-se mais fácil impedir que essas pessoas - e seus "aliados" - organizem-se em torno de um projeto de sociedade que vise superar as relações sociais capitalistas - exatamente as próprias relações sociais que não só produzem a "exclusão", como também impedem a erradicação desse fenômeno. A outra função ideológica da formulação apresentada consiste em uma tentativa de convencer as pessoas pertencentes à classe trabalhadora de que os capitalistas devem ser vistos como parceiros e não como indivíduos pertencentes a uma classe antagônica, possuidora de interesses também antagônicos. Dessa maneira, torna-se mais fácil amenizar os conflitos de classe. Em ambos os casos, está expressa a tentativa de difundir referências que garantam a coesão social através da subordinação ideológica dos indivíduos à dominação capitalista.

A chamada inclusão social no mercado de trabalho é apenas uma das formas pelas quais o princípio da inclusão tem se manifestado. Já foi mencionado anteriormente que o processo de inclusão busca se efetivar nos "sistemas sociais gerais da sociedade" e que a disseminação desse processo teria como objetivo a construção da chamada sociedade inclusiva. Esta, também chamada de "sociedade para todos", seria composta por sistemas sociais gerais "inclusivos", que dariam forma a um "novo tipo de sociedade". Porém, ao refletir sobre a inclusão no mercado de trabalho, torna-se possível compreender que esse processo não visa construir um novo tipo sociedade. Evidência disso é o fato de que a chamada empresa inclusiva, que aparentemente se manifesta como algo que valoriza a diversidade humana, mantém a mesma essência da "empresa comum": visa explorar os seres humanos de modo a agregar valor ao capital. Esse modelo de empresa, dita inclusiva, ainda é regida pelas leis capitalistas. Isso evidencia que a inclusão não visa construir um novo tipo de sociedade, mas sim promover alterações que mantenham a natureza das relações sociais vigentes.

A atitude de atribuir outras denominações à sociedade capitalista é uma ação que segue a tendência do atual ambiente ideológico, porém, como se trata de uma atitude que não capta a essência dos processos históricos, deveria restringir-se apenas àqueles que compartilham a adoção do subjetivismo, do idealismo e de outras categorias que satisfazem à ideologia específica do neoliberalismo ${ }^{5}$. Nesse ponto, faz-se necessário mencionar uma das formulações de Newton Duarte sobre o tema, por considerar que ela expressa bem a postura a ser tomada diante da utilização de denominações que vêm ganhando crescente espaço em nossos dias, tais como, "sociedade do conhecimento", "sociedade pós-industrial", "sociedade da informação" etc. Nas palavras do autor:

Sequer cogitarei a possibilidade de fazer qualquer concessão à atitude idealista, para a qual a denominação que empregamos para caracterizar nossa sociedade dependa do "olhar" pelo qual focamos essa sociedade: se for o "olhar econômico" então podemos falar em capitalismo, se for o "olhar político" devemos falar em sociedade democrática, se for o "olhar cultural" devemos falar em sociedade pós-moderna ou sociedade do conhecimento ou sociedade multicultural ou sei lá quantas outras denominações. Essa é uma atitude idealista, bem a gosto do ambiente ideológico pós-moderno (DUARTE, 2003, p.13).

Conforme explica Duarte (2003), o capitalismo do final do século XX e início do século XXI passa por mudanças que nos permitem considerar que estejamos vivenciando uma nova fase do capitalismo. Entretanto, o autor ressalta que isso não significa uma alteração da essência da sociedade capitalista. Daí a inconsistência da adoção de termos como os citados anteriormente, que expressam a ideia de que alterações superficiais significam a consolidação de um outro tipo de sociedade, não mais regido pelas relações 
sociais capitalistas. De acordo com o autor, a "assim chamada sociedade do conhecimento é uma ideologia produzida pelo capitalismo, é um fenômeno no campo da reprodução ideológica do capitalismo" (DUARTE, 2003, p.13). Da mesma forma, acontece com a assim chamada "sociedade inclusiva". Trata-se de mais uma denominação que visa reforçar as relações capitalistas através de processos educativos.

As reflexões sobre a tese em questão buscaram evidenciar que o processo de inclusão social não contribui para construir um novo tipo de sociedade, radicalmente diferente da qual vivemos atualmente; pelo contrário, atua de modo a manter a velha ordem social capitalista. Apesar das modificações propostas pela inclusão significarem um processo que traz alterações na sociedade, essas alterações não mudam a natureza das relações sociais e do modo de produção vigente. Portanto, não são suficientes para eliminar os fatores que produzem a "exclusão" e mantêm "excluídas" certas pessoas da sociedade. O que a inclusão propõe é um processo de mudanças superficiais. Por isso, é uma atitude idealista denominar de "sociedade inclusiva" um modo de produzir a vida essencialmente regulado pelo capital. A assim chamada "sociedade inclusiva não passa, pois, de uma forma aparente da sociedade capitalista em uma nova fase, a do suposto "capitalismo humanizado". Em linhas gerais, pode-se afirmar que a implicação ideológica central da tese em questão consiste em uma tentativa de reafirmar a viabilidade de humanização do capitalismo.

Tese 2: a inclusão equipara as oportunidades e torna os serviços sociais gerais da sociedade acessíveis para todos

Neste momento, busca-se refletir sobre a tese de que a inclusão é capaz de possibilitar o acesso de todas as pessoas aos serviços oferecidos pela sociedade, assim como aos bens produzidos historicamente pela humanidade. Para tanto, foram adotadas, como ponto de partida, algumas reflexões sobre um dos pilares da inclusão: o conceito de "equiparação de oportunidades".

Sassaki (2005) explica que a semente do paradigma da inclusão foi plantada quando uma organização não-governamental criada por líderes com deficiência - a Disabled Peoples 'International - definiu a equiparação de oportunidades. Esse conceito é definido como

$\mathrm{O}$ processo mediante o qual os sistemas gerais da sociedade, tais como o meio físico, a habitação e o transporte, os serviços sociais e de saúde, as oportunidades de educação e de trabalho, e a vida cultural e social, incluídas as instalações esportivas e de recreação, são feitos acessíveis para todos. Isto inclui a remoção de barreiras que impedem a plena participação das pessoas deficientes em todas estas áreas, permitindo-lhes assim alcançar uma qualidade de vida igual à de outras pessoas (Driedger e Enns apud Sassaki, 1999, p.39).

Aparentemente, a chamada equiparação de oportunidades pode ser considerada um avanço, sobretudo porque as modificações defendidas por esse processo podem atender às necessidades imediatas de algumas pessoas que estariam impedidas de ocupar alguns ambientes, caso tais modificações não fossem realizadas.

Conforme explica Sassaki (1999), desde a década de 1960, tem-se vivenciado um movimento pela eliminação ou modificação de barreiras arquitetônicas. No início, o movimento buscou chamar a atenção para a existência desses obstáculos e para a necessidade de eliminá-los ou reduzi-los ao mínimo possível, o que culminou com o 
conceito de "adaptação do meio físico". Tratava-se de adaptar os ambientes físicos, os transportes e os produtos já existentes, de modo a se tornarem utilizáveis não só pelos portadores de deficiência, mas também pelas pessoas obesas, as de baixa estatura, as idosas e as temporariamente impossibilitadas de deambular. Daí a referência a termos como "prédio adaptado", "ônibus adaptado", "restaurante adaptado" etc. (SASSAKI, 1999). Com o passar dos anos, a luta pela adaptação do meio físico deu lugar, segundo o autor, à luta baseada em dois outros conceitos.

O primeiro deles foi o chamado "desenho acessível". Esse conceito surgiu a partir do questionamento de que, ao mesmo tempo em que ambientes físicos já construídos eram adaptados, novos ambientes inacessíveis iam sendo criados. $\mathrm{O}$ autor explica que o desenho acessível defendeu a construção de projetos que levassem em conta a acessibilidade especificamente voltada para as pessoas com deficiência, de modo que elas pudessem utilizar os ambientes físicos e os transportes com autonomia e independência. Daí denominações como "prédio acessível" e "ônibus acessível" para se referir àqueles já construídos sob a ótica da acessibilidade.

Outro conceito apontado por Sassaki (1999), o "desenho universal”, é mais recente na luta pela acessibilidade. No entendimento do autor, o desenho universal poderia também ser chamado de "desenho inclusivo", visto que, dentro do movimento da inclusão, ele é pensado como um "projeto que inclui todas as pessoas", ou seja, "os produtos e ambientes feitos com desenho universal ou inclusivo não parecem ser especialmente destinados a pessoas com deficiência. Eles podem ser utilizados por qualquer pessoa, deficiente ou não" (SASSAKI, 1999, p. 141).

A afirmação de que a equiparação de oportunidades pode ser considerada um avanço sustenta-se no entendimento de que o chamado "desenho inclusivo", preconizado pela inclusão, amplia as possibilidades de acesso àqueles que antes estavam impedidos. Por exemplo, uma pessoa que utiliza cadeira de rodas para se locomover teria poucas possibilidades de transitar pelas ruas, prédios, cinemas, teatros, escolas, hospitais etc., caso esses espaços apresentassem barreiras arquitetônicas. Ao modificar os espaços físicos com base no desenho universal, a equiparação de oportunidades amplia as possibilidades de acesso. Mas, sob a ótica da inclusão, a chamada equiparação de oportunidades vai além de uma mera modificação dos espaços físicos, visto que ela seria capaz de tornar os serviços da sociedade acessíveis para todas as pessoas. Essa ideia pode ser captada, por exemplo, na afirmação de Sassaki (1999, p.41): "É fundamental equipararmos as oportunidades para que todas as pessoas, incluindo portadoras de deficiência, possam ter acesso a todos os serviços, bens, ambientes construídos e ambientes naturais". Dois aspectos devem ser ressaltados a partir dessas palavras do autor. O primeiro diz respeito à identificação de que nem todas as pessoas podem ter acesso a todos os serviços oferecidos pela sociedade. De fato, as condições de vida no capitalismo impossibilitam o acesso universal não só aos serviços oferecidos, como aos bens produzidos pela própria humanidade. Porém, embora os teóricos da inclusão identifiquem a falta de acesso, eles não a relacionam com a dinâmica capitalista. Consequentemente, sua tentativa de superá-la esbarra nas determinações essenciais desse fenômeno. Evidência disso é o segundo aspecto a ser mencionado: a inclusão defende a equiparação de oportunidades como forma de garantir o acesso de todos aos serviços, bens e ambientes construídos e naturais da sociedade.

Conforme mencionado anteriormente, no capitalismo tudo tende a se tornar mercadoria. Isso nos permite afirmar que, embora os serviços de transporte, por exemplo, sejam responsáveis pelo deslocamento de uma grande quantidade de pessoas diariamente, quando um empresário oferece tal serviço, ele não o faz para atender essencialmente às necessidades humanas, mas, sim, para produzir capital. A princípio, muitas pessoas 
necessitam fazer uso de serviços de transporte como, por exemplo, ônibus e metrô. Contudo, nem todas podem utilizá-los, visto que, na sociedade capitalista, esse serviço também é oferecido como uma mercadoria, estando, portanto, destinado apenas aos que possuem condições de consumi-lo. Exatamente devido ao fato de que os serviços oferecidos e bens produzidos no capitalismo não são disponíveis para todas as pessoas, é possível compreender a contradição no serviço de transporte em regiões mais avançadas no Brasil: "estrutura de transporte urbano nos moldes dos países ricos, mas que condena, por falta de dinheiro, milhões de pessoas a caminharem, como andarilhos medievais, os quilômetros entre suas pobres casas e o trabalho" (BUARQUE, 1991, p.19). Essa constatação evidencia o fato de que a lógica capitalista impede o acesso de todas as pessoas ao serviço de transporte, visto que nem todos podem consumi-lo.

Nesse ponto, é importante salientar que o princípio da inclusão não é capaz de promover o acesso de todos aos serviços oferecidos e bens produzidos no capitalismo, simplesmente pelo fato de que a chamada sociedade inclusiva, como já foi possível entender, nada mais é do que a sociedade capitalista com uma nova aparência. Ou seja, a inclusão não ataca a lógica que impede a acessibilidade de todas as pessoas às produções da humanidade. Evidência disso é que a construção de "ônibus inclusivos", pautados no "desenho universal", no "transporte para todos", não passa de uma ampliação do serviço de transporte capaz de possibilitar a incorporação de novos consumidores. Ou seja, embora a construção de "ônibus inclusivos" ou "ônibus adaptados" amplie a possibilidade de locomoção das pessoas que utilizam cadeira de rodas, por exemplo, permitindo a elas utilizar um serviço que antes lhes era impedido, isso não significa uma alteração da lógica que rege o funcionamento desse serviço. Consequentemente, não significa que tal serviço esteja efetivamente acessível para todos, pois o acesso ao transporte inclusivo mantém-se restrito aos que possuem condição de consumo. Outra evidência disso pode ser extraída das seguintes palavras de Sassaki (1999, p. 142):

\begin{abstract}
Após uma fase em que predominaram as adaptações feitas nas calçadas e em alguns ônibus ou peruas (vans), as quais têm evidente aparência de providência destinada a pessoas com deficiência, estamos na fase em que cada vez mais espaços urbanos e meios de transporte já estão sendo planejados e construídos de tal forma que neles não se nota nada de especial. Isto constitui um dos sinais do surgimento de uma sociedade inclusiva.
\end{abstract}

Ao afirmar que um dos sinais do surgimento da sociedade inclusiva refere-se às modificações superficiais - referentes ao planejamento e construção - dos espaços urbanos e dos meios de transporte, o autor evidencia a compreensão de que tais modificações, que não alteram a lógica dos serviços oferecidos, são suficientes para indicar o surgimento de uma "nova sociedade".

Conforme consta na definição do conceito de equiparação de oportunidades, a habitação também é mencionada como um dos sistemas sociais gerais da sociedade que se tornaria acessível para todos com a implementação do processo de inclusão. Mas, do mesmo modo que acontece com os serviços de transporte, acontece com a habitação: a lógica capitalista transforma a habitação em mercadoria. Dessa forma, a construção de casas e prédios com "desenho inclusivo" - ou seja, com portas mais largas, banheiros e elevadores com "desenho universal" - não garante que todas as pessoas tenham, efetivamente, acesso à habitação. A partir das palavras de Mclaren e Farahmandpur (2002), torna-se possível visualizar que a "falta de moradia" nos dias de hoje, decorrente da lógica capitalista, tem atingido inclusive países de capitalismo central: 
As contradições do capital em geral e as imperfeições do mercado nos países "capitalisticamente" avançados do Ocidente são especialmente evidentes em toda parte dos Estados Unidos. Hoje, aproximadamente 700 mil pessoas são desabrigadas em qualquer noite nesse país. Anualmente, dois milhões de pessoas experimentam o abandono sem-teto. Tragicamente, uma de cada quatro pessoas desabrigadas é uma criança inocente. Numa maioria das largas cidades metropolitanas em todo país, estar nas ruas sem teto é considerado crime. Variados métodos têm sido implementados para tornar visíveis as pessoas desabrigadas. Em Chicago, por exemplo, as pessoas desabrigadas são perseguidas e presas diariamente. Essas são casualidades sem cerimônia da ex-comunicação econômica. A campanha "qualidade de vida" do prefeito de Nova York, Rudolph Giulani, envolve afastar e reprimir pessoas desabrigadas para ter certeza de que elas não passarão dos bairros pobres para os ricos de Nova York. Em São Francisco, 16 mil multas de violação foram aplicadas a pessoas desabrigadas. Em Tucston, Arizona, oficiais da cidade estão considerando a possibilidade de privatização das calçadas da cidade na área do distrito de negócios por um dólar, tornado, assim, ato ilegal as pessoas desabrigadas deitarem ou sentarem nas calçadas (MCLAREN e FARAHMANDPUR, 2002, p. 28-29).

Conforme sugere a afirmação dos autores, o desenvolvimento da lógica capitalista pode levar até mesmo à privatização das calçadas. Tal fato ampliaria ainda mais a nãoacessibilidade promovida pelo capital, pois até mesmo a calçada (seja ela "adaptada", "acessível" ou "inclusiva") teria acesso restrito aos que possuem o privilégio de consumo.

Em relação à educação e saúde, também enfatizados pelo conceito de equiparação de oportunidades, pode-se dizer que, no interior do capitalismo, tais serviços não são oferecidos à população de modo que cada indivíduo possa escolher conforme o padrão que bem entender. Educação e saúde também se tornaram mercadoria, passando a ser oferecidos com padrões distintos de qualidade. Em virtude disso, quem possui o privilégio de consumo e pode pagar a mais por tais serviços, pode escolher entre as diversas opções oferecidas.

Nesse ponto, é importante ressaltar outra ideia veiculada pelo princípio da inclusão social: trata-se da tese de que a inclusão equipara oportunidades, ou seja, de que é possível equiparar oportunidades no interior do capitalismo. Ao desconsiderar que a desigualdade resultante das relações capitalistas favorece os que possuem maior capacidade de consumo, impossibilitando uma efetiva equiparação de oportunidades, a inclusão social contribui para disseminar o princípio da liberdade de mercado. Esse princípio entende que a liberdade de mercado premia os indivíduos mais capazes e aptos de acordo com o esforço próprio de cada um (ANDERSON, 1998). Trata-se de um entendimento que desconsidera a desigualdade de condições provenientes das diferenças de classe. No capitalismo, ao "esforço próprio de cada um" somam-se as condições de vida delineadas pela posição ocupada nas relações capitalistas. $\mathrm{O}$ entendimento de que a liberdade de mercado premia os indivíduos mais capazes e aptos de acordo com o esforço próprio de cada um mantém como lacuna o fato de que os indivíduos pertencentes à classe dominante e, até mesmo, os pertencentes às frações mais privilegiadas da classe trabalhadora se inserem nos processos competitivos com ampla vantagem frente a seus concorrentes. Sem superar a divisão da sociedade em classes sociais, não é possível equiparar efetivamente as oportunidades, simplesmente porque a concorrência entre os indivíduos no capitalismo ocorre em desigualdade de condições. O paradigma da inclusão, como já foi possível compreender, defende a inserção das pessoas com deficiência no mercado de trabalho, nas escolas 
regulares etc., o que amplia a participação dos indivíduos pertencentes a esse grupo historicamente discriminado na vida social. Contudo, afirmar que isso se trata de uma equiparação de oportunidades significa desconsiderar a desigualdade de condições produzida pelo capitalismo.

Outro ponto a ser destacado sobre o conceito de equiparação de oportunidades refere-se à sua ênfase na remoção de barreiras que estariam impedindo as pessoas com deficiência de alcançar uma qualidade de vida igual à de outras pessoas.

É importante salientar que as barreiras a que se refere o princípio da inclusão centram-se em determinantes não essenciais, isto é, secundários. No capitalismo, o acesso às produções culturais é restrito a uma parcela da população, àquela que pode consumir. É por isso que as modificações proposta pela inclusão não garantem o acesso de todos. Ao remover as barreiras defendidas pela inclusão, é provável que aquelas pessoas com necessidades especiais que possuem condições de vida privilegiadas sejam beneficiadas com essa ação, podendo acessar - com autonomia e independência - os serviços bancários, de transporte, os museus, os cinemas, assim como o conhecimento sistematizado disponível em livros, por exemplo. Contudo, não se pode dizer o mesmo a respeito daquelas pessoas que vivem de forma dramática os efeitos da exploração, sejam elas portadores de necessidades especiais ou não. Em essência, o acesso aos bens materiais e imateriais depende da posição ocupada por cada indivíduo nas relações sociais capitalistas. Um indivíduo com necessidades especiais que vive da exploração de outras pessoas tem maior possibilidade de melhorar sua qualidade de vida, de acessar os serviços e bens disponíveis na sociedade do que as pessoas que mal têm asseguradas suas condições mínimas de sobrevivência. Se, por um lado, é importante promover a remoção das barreiras a que se refere a inclusão, por outro lado, isso não é suficiente para garantir o acesso de todos, pois a dinâmica do capitalismo é essencialmente oposta à socialização universal e não mercantilizada dos bens produzidos pela humanidade. Em segundo lugar, é importante salientar que, se existe a necessidade de remover barreiras para que os deficientes possam alcançar uma qualidade de vida "igual à de outras pessoas", o primeiro passo a ser dado deve ser a definição de quais são as outras pessoas a que está se fazendo referência, ou melhor, a que classe social tais pessoas pertencem, visto que os efeitos do mercado têm degradado a vida de grande parte da classe trabalhadora mundial. Condições precárias de vida, expressas pela miséria, por exemplo, atingem a classe trabalhadora em geral, que tem sentido os efeitos devastadores da ofensiva do capital, sobretudo a partir da crise dos anos de 1970. Também é importante lembrar que o capitalismo sustenta-se na exploração, o que permite à classe dominante viver à custa do trabalho dos que, não possuindo meios de produção, são obrigados a vender sua força de trabalho para sobreviver. Esse fato torna evidente que as condições de vida de um indivíduo qualquer, deficiente ou não, variam de acordo com a posição ocupada nas relações capitalistas, tal como evidencia Lancillotti (2003, p.91):

Um sujeito deficiente, que tem condições de se beneficiar dos avanços tecnológicos para compensar seus limites, com o uso de próteses ou órteses adequadas, freqüentando serviços de saúde e escolares que melhor atendam às suas necessidades ou mesmo estruturando seu próprio negócio, estaria em condições muito vantajosas ante aqueles que mal tem condições de ver asseguradas suas necessidades básicas de sobrevivência.

As contradições de classe produzem desigualdade na sociedade. Tal desigualdade impede uma efetiva equiparação de oportunidades. Frigotto (2001) explica que ficam cada vez menos racionalmente justificáveis as políticas que induzem à não-produção de 
alimentos, remédios, assim como sua destruição, em nome da saúde do mercado, dos estoques reguladores e das taxas médias do lucro do capital. Essas políticas a que se refere o autor evidenciam que, no modo de produção capitalista, as produções culturais não são destinadas às necessidades humanas da maior parte da população, mas ao mercado - de modo a atender ao interesse de uma classe social que, embora seja pouco numerosa, possui grande condição econômica e poder político. Como o mercado não é para todos, apenas algumas pessoas poderão acessar àquilo que ele oferece. Da mesma forma que não interessa ao capital socializar alimentos, medicamentos e outras mercadorias, também não é de seu interesse socializar serviços com o mesmo padrão de qualidade, visto que ao capital interessa transformar as produções humanas em mercadoria. E, conforme ressalta Anderson (1998, p. 199), em serviços como educação, saúde e trabalho, "não há qualquer possibilidade de que o mercado possa prover nem sequer o mínimo requisito de acesso universal aos bens imprescindíveis em questão".

Tendo em vista a impossibilidade de socializar o acesso no interior da ordem social vigente e levando em consideração que a inclusão não visa superar o modo como homens e mulheres produzem sua existência nos dias de hoje, é possível afirmar que a acessibilidade defendida pela inclusão segue a tendência da "igualdade de acesso" já analisada por Platt (2004), temática que, segundo ela, é pertinente aos discursos plásticos e vazios que redundam na não-acessibilidade dos sujeitos ao mercado, sendo restrito somente aos que podem consumir os serviços oferecidos.

A tese de que "a inclusão equipara oportunidades e torna os serviços sociais gerais da sociedade acessíveis para todos" tem a implicação ideológica de mascarar o fato de que as barreiras que impedem o pleno acesso de todos aos serviços oferecidos pela sociedade e aos bens produzidos pela humanidade são impostas pela sociedade capitalista. Dessa forma, torna-se mais fácil difundir o entendimento de que mudanças superficiais no capitalismo são capazes de promover o acesso de todos os indivíduos à riqueza material e intelectual da humanidade, independentemente da classe social a que pertencem.

\section{Inclusão social: uma ideologia articulada à nova pedagogia da hegemonia}

Se sempre o domínio envolveu o manejo da ideologia, há novos elementos nas estratégias de domínios atuais, que exigem uma mirada teórica inovadora sobre a problemática da ideologia. O deslocamento da exploração/expropriação para exclusão/inclusão é decisivo. A partir dessa caracterização, todo um enorme aparato de idéias é difundido para que os ditos excluídos possam vislumbrar a possibilidade de inclusão social (LEHER, 2010, p.12).

As reflexões apresentadas anteriormente nos permitem afirmar que o paradigma da inclusão se constitui como uma ideologia. Segundo Mészáros (2004), a ideologia é uma consciência social que não só manifesta interesses como também exerce forte influência nos processos materiais. O autor explica que toda ideologia está ancorada nas condições materiais da sociedade, sendo orientada para a prática social. Com a inclusão social não é diferente. Essa ideologia surge de uma necessidade social concreta, qual seja, a de superar a exclusão. Não faria muito sentido defender a inclusão se o problema da "exclusão social" não existisse. A defesa da sociedade inclusiva, da equiparação de oportunidades e de outras noções relacionadas à inclusão só ganham sentido com a constatação de que existem problemas sociais a serem tratados. Diante da constatação desses problemas, a ideologia da 
inclusão social, como já foi possível compreender, busca orientar as pessoas para atuarem na prática social em conformidade com princípios que mantêm intocadas as bases do capitalismo. Ao reduzir o conflito à diferença entre indivíduos, a inclusão social busca fortalecer a coesão social nos parâmetros estruturais da sociedade capitalista. Através da difusão de um conjunto de formulações, que não só apresentam uma leitura da realidade, mas, também, indicam uma linha possível de ação, a ideologia em questão apresenta representações (idéias e valores) e normas (de conduta) que indicam e prescrevem aos membros da sociedade o que e como devem pensar, valorizar e, ainda, como devem agir, sempre no sentido de subordinar diferentes grupos sociais à hegemonia do bloco no poder.

Para reforçar os processos ideológicos que afirmam a hegemonia burguesa, a ideologia da inclusão aborda a exclusão social sem evidenciar que esse fenômeno é determinado pelas relações capitalistas de produção da existência humana. Ao mesmo tempo, para reforçar o sentido de repolitização da política, indica uma linha de ação que trata os problemas sociais sem alterar as bases fundamentais do capitalismo. Assim, por meio dessa dupla intencionalidade, a ideologia da inclusão social acaba integrando a função educativa desempenhada pela nova pedagogia da hegemonia: de assegurar a dominação de classe por meio do convencimento, garantindo a coesão social nos moldes de uma nova sociabilidade. Pode-se afirmar, então, que a inclusão social nada mais é do que uma construção ideológica, que se articula aos processos pedagógicos de formação da nova sociabilidade para afirmar a hegemonia burguesa.

\section{Nota conclusiva}

As reflexões apresentadas neste texto indicam que o chamado paradigma da inclusão é uma ideologia articulada à nova pedagogia da hegemonia. Embora proponha avanços no sentido de melhorar as condições de vida de grupos sociais específicos, a inclusão social não altera as bases do modo de produção capitalista da existência. A difusão de suas concepções e ações tende a reforçar a coesão social através de processos educativos positivos, fazendo com que os ditos excluídos passem a vislumbrar a possibilidade de serem incluídos. Essa ideologia reproduz manifestações fenomênicas como sendo o produto concreto da realidade, de modo a desorganizar a compreensão crítica do real e afirmar a manutenção do capitalismo por meio do convencimento. O texto comprova que conceitos como "sociedade inclusiva", "equiparação de oportunidades" e "empresa inclusiva" expressam uma tentativa de afirmar a viabilidade de um capitalismo mais humano. A difusão desses conceitos pelo tecido social fortalece um processo educativo que legitima ideias conservadoras, enfraquece as críticas ao capitalismo, debilita a luta pela superação desse modo de produção da existência e, ainda, indica ações que não abordam os problemas sociais em sua radicalidade.

\section{Referências}

ANDERSON, Perry. Além do neoliberalismo. In: GENTILI, Pablo; ANDERSON, Perry. Pós-neoliberalismo: as políticas sociais e o Estado democrático. 4. ed. São Paulo: Paz e Terra, 1998.

BUARQUE, Cristóvam. O colapso da modernidade brasileira: e uma proposta alternativa. São Paulo: Paz e Terra, 1991. 
CHAUÍ, Marilena. Escritos sobre a universidade. São Paulo: Editora UNESP, 2001.

COSTA, Áurea de Carvalho. Anônimas odisséias: a dupla destituição do direito à educação e ao trabalho na infância e na vida adulta. São Paulo: Anna Blume, 2005.

DUARTE, Newton. Sociedade do conhecimento ou sociedade das ilusões? Campinas: Autores Associados, 2003.

EAGLETON, Terry. Depois da teoria: um olhar sobre os estudos culturais e o pósmodernismo. Rio de Janeiro: Civilização Brasileira, 2005.

FONTES, Vigínia. Reflexões im-pertinentes: história e capitalismo contemporâneo. Rio de Janeiro: Bom texto, 2005.

FRIGOTTO, Gaudêncio. A nova e a velha faces da crise do capital e o labirinto dos referenciais teóricos. In: FRIGOTTO, Gaudêncio; CIAVATTA, Maria (orgs.). Teoria e educação no labirinto do capital. 2 ed. Petrópolis: Vozes, 2001.

GRAMSCI, Antonio. Cadernos do cárcere. Vol 1. Introdução ao estudo da filosofia. A filosofia de Benedetto Croce. Rio de Janeiro: Civilização Brasileira, 1999.

GRAMSCI, Antonio. Cadernos do cárcere. Vol. 3. Maquiavel. Notas sobre o Estado e a política. Rio de Janeiro: Civilização Brasileira, 2000.

GUIDDENS, Anthony. A terceira via: reflexões sobre o impasse político atual e o futuro da social-democracia. 4. ed. Rio de Janeiro: Record, 2001a.

GUIDDENS, Anthony. A terceira via e seus críticos. Rio de Janeiro: Record, 2001b.

GUIDDENS, Anthony. Para além da esquerda e da direita: o futuro da política radical. São Paulo: Editora da UNESP, 1996.

HARVEY, David. Condição pós-moderna. Uma pesquisa sobre as origens da mudança cultural. 16. ed. São Paulo: Loyola, 2007.

LANCILLOTTI, Samira Saad Pulchério. Deficiência e Trabalho. Campinas: Autores Associados, 2003.

LEHER, Roberto. Prefácio. Uma penetrante perspectiva teórica para compreender como os dominantes dominam. In: NEVES, Lúcia Maria Wanderley (org.). A direita para o social e esquerda para o capital: intelectuais da nova pedagogia da hegemonia no Brasil. São Paulo: Xamã, 2010.

MARTINS, André Silva. A direita para o social: a educação da sociabilidade no Brasil contemporâneo. Juiz de Fora: Editora da UJFJ, 2009.

MARTINS, André Silva. O Estado educador e a Nova Pedagogia da Hegemonia. Juiz de Fora: 2010 (mimeo).

MARTINS, Andre Silva; NEVES, Lúcia Maria Wanderley. A nova pedagogia da hegemonia e a formação/atuação de seus intelectuais orgânicos. In: NEVES, Lúcia Maria Wanderley (org.). A direita para o social e esquerda para o capital: intelectuais da nova pedagogia da hegemonia no Brasil. São Paulo: Xamã, 2010.

MCLAREN, Peter; FARAHMANDPUR, Ramin. Pedagogia revolucionária na globalização. Rio de Janeiro: DP\&A, 2002.

MÉSZÁROS, István. O poder da ideologia. São Paulo: Boitempo, 2004. 
NEVES, Lúcia Maria Wanderley (org.). A nova pedagogia da hegemonia: estratégias da burguesia brasileira para educar o consenso na atualidade. São Paulo: Xamã, 2005.

NEVES, Lúcia Maria Wanderley (org.). Direita para o social e esquerda para o capital: intelectuais da nova pedagogia da hegemonia no Brasil. São Paulo: Xamã, 2010.

OLIVEIRA, Avelino da Rosa. Marx e a exclusão. Pelotas: Seiva, 2004a.

OLIVEIRA, Avelino da Rosa, (2004b). Sobre o alcance teórico do conceito "exclusão". Civitas, v.4, n.1, p.1-30.

PINA, Leonardo Docena; MARTINS, André Silva, (2010). Implicações da crise capitalista no campo teórico: pós-modernidade e exclusão social das pessoas com deficiência. Trabalho necessário, v.10, p.1-29.

PLATT, Adreana Dulcina. O paradigma inclusivo das políticas educacionais e o paradigma excludente das políticas econômicas nos anos 90: o constructo sócio-conceitual da normalidade/anormalidade (ou adequação social). Tese (Doutorado em Educação). Campinas: Faculdade de Educação, Universidade Estadual de Campinas, 2004.

SANCHEZ, Pilar Arnaiz, (2005). A educação inclusiva: um meio de construir escolas para todos no século XXI. In: Inclusão. Revista da Educação especial. v.1, n.1, p.7-18.

SASSAKI, Romeu Kazumi. Inclusão. Construindo uma sociedade para todos. Rio de Janeiro: WVA, 1999.

SASSAKI, Romeu Kazumi, (2005). Inclusão: o paradigma do século XXI. Inclusão. Revista da Educação especial. v. 1, n. 1, p.19-23.

Notas:

* O autor é mestre em Educação (UFJF), professor de educação física da Rede Pública Municipal de Ensino de Juiz de Fora/MG e integrante do Núcleo de Estudos sobre Trabalho e Educação da Universidade Federal de Juiz de Fora.

1 Segundo Martins (2009), sociabilidade ou conformismo social corresponde à forma com que os homens e as classes produzem e reproduzem as condições objetivas e subjetivas de sua própria existência, sob mediação das bases concretas de produção, de uma dada direção política e do estágio de correlação de forças presentes num certo contexto. Nesta acepção, a forma de ser, pensar e agir predominante em determinado momento histórico é marcada por traços comuns ou compartilhados pelo conjunto de seres humanos, sob mediação do estágio de desenvolvimento das relações sociais.

2 Os fundamentos centrais da Terceira Via podem ser obtidos em Guiddens (1996), Guiddens (2001a) e Guiddens (2001b).

3 Por repolitização da política entende-se a redefinição da participação política no contexto democrático das décadas finais do século XX e iniciais do século XXI, voltadas ao fortalecimento da coesão social nos moldes do neoliberalismo da Terceira Via (NEVES, 2005).

4 Oliveira (2004a), Oliveira (2004b), Fontes (2005) e Costa (2005) também fornecem importantes contribuições ao debate sobre exclusão social. Destaco o estudo de Pina e Martins (2010) porque enfatiza as condições de inferioridade social das pessoas com deficiência, exatamente a expressão da "exclusão" enfatizada por Sassaki (1999), intelectual cujas ideias centrais são analisadas neste texto.

5 De acordo com Chauí (2001), o pós-modernismo assume o papel de ideologia específica do neoliberalismo.

Recebido em: $\quad 28 / 10 / 10$

Aprovado em: $14 / 12 / 10$ 